\title{
Imaginación, creatividad y aprendizaje por descubrimiento a través del arte en educación infantil.

\author{
Imagination, creativity and discovery learning through art in early \\ childhood education.
}

\author{
Jessica Rodríguez Cristino \\ Doctorando en la Universidad de \\ Jaén, España \\ jessicarocri@gmail.com
}

\author{
Recibido 21/01/2017 \\ Revisado 27/05/2017 \\ Aceptado 28/05/2017 Publicado01/07/2017
}

\section{RESUMEN}

Este artículo presenta una forma de aprendizaje a través del arte en la etapa de Educación Infantil. El arte es una herramienta crucial para lograr aprendizajes significativos y que perdurarán en el recuerdo de los más pequeños a lo largo de toda su vida, porque ellos habrán sido los protagonistas de sus procesos de enseñanza y de aprendizaje. Se trata de desarrollar la creatividad de estos, la imaginación y la curiosidad mediante la experimentación, el aprendizaje por descubrimiento, la manipulación y el empleo de los cinco sentidos.

El objetivo fundamental es presentar una manera diferente y atractiva de trabajar en las aulas cualquier contenido a través del arte mediante las "instalaciones artísticas" y formar a los educadores en ello. Una vez expuesta la parte teórica y fundamentada se
ABSTRACT

This article presents a way of learning through art in the kindergarten stage. Art is a crucial tool to achieve significant learning and that will last in the memory of the little ones throughout their lives because they have been the protagonists of their teaching and learning. It is about developing creativity of these, imagination and curiosity through experimentation, discovery learning, handling and use of the five senses.

The main objective is to present a different and attractive way to work in the classroom any content through art by the "artistic installations" and train educators about it. Once exposed the theoretical and research based part through the arts held for three months in a classroom of children Children aged between 3 and 4 years old and whose real practice in that school will be presented called "Niña

\section{Para citar este artículo,}

Rodríguez Cristino, J. (2017). Imaginación, creatividad y aprendizaje por descubrimiento a través del arte en educación infantil. Tercio Creciente, 12, págs. 97-120. DOI: 10.17561/rtc.n12.7 
DOI: $10.17561 /$ rtc.n12.8

Investigación

presentará una investigación a través de las artes llevada a cabo durante tres meses en un aula de Infantil de niños y niñas de entre 3 y 4 años de edad y cuya práctica real en dicho colegio llamado "Niña María” de Linares (Jaén) duró dos días. Finalmente, para concluir el trabajo se recogen los resultados
http://revistaselectronicas.ujaen.es/index.php/RTC/index www.terciocreciente.com
María” Linares (Jaén) lasted two days. Finally, to complete the work, the results obtained are presented.

Palabras clave / Keywords

Instalaciones artísticas, aprendizaje por descubrimiento, experiencias artísticas, emociones / Art installations, discovery learning, artistic experiences, emotions.

\section{Para citar este artículo,}

Rodríguez Cristino, J. (2017). Imaginación, creatividad y aprendizaje por descubrimiento a través del arte en educación infantil. Tercio Creciente, 12, págs. 97-120. DOI: 10.17561/rtc.n12.7 


\section{Imaginación, creatividad y aprendizaje por descubrimiento a través del arte en educación infantil.}

\section{Introducción:}

Este artículo da cuenta de una investigación educativa llevada a cabo en el centro "Niña María” de Linares (Jaén) a partir de un proyecto realizado en colaboración con cuatro futuras maestras de Educación Infantil (Barba González, Elena; Delgado Salido, Sara; Carrasco Castillo, María V. y Flores Flores, Carmen) que se han interesado por esta investigación.

El arte ha quedado dentro del ámbito educativo un poco olvidado, ya que se le está dando más relevancia a las áreas de contenidos troncales y menos a aquellas que se consideran auxiliares o complementarias.

En cambio con este trabajo queremos posicionar el arte en un lugar privilegiado, pues a través de este podemos perfectamente desarrollar el resto de áreas troncales y complementarias, así como los temas transversales.

Según Read (1986: 38; citado en Gutiérrez Pac, 2013-2014: 17):

El arte es una de esas cosas que, como el aire o el suelo, está a nuestro alrededor en todas partes, pero que raramente nos detenemos a considerar. El arte está presente en todo lo que hacemos para agradar a nuestros sentidos.

Se trata de demostrar que es una herramienta crucial para lograr aprendizajes significativos y motivadores. Concretamente, nos hemos interesado en una nueva forma de trabajar con el arte que se le ha llamado "instalaciones artísticas". Estas consisten en transformar un espacio cualquiera en un lugar totalmente diferente, lúdico y atractivo. Nos centramos en las aulas, lugar de trabajo de los niños y de las niñas de Infantil.

Se trata de crear un espacio en el cual los más pequeños puedan vivenciar y percibir sensorialmente un entorno lúdico y estético con el que puedan interaccionar, aprender e interiorizar los contenidos que se pretendan alcanzar con los objetivos didácticos propuestos. Los niños y las niñas descubren por sí solos y juegan a la vez que adquieren conocimientos y valores, los docentes solo observan y anotan lo que sucede en ese momento.

Nuestras referencias y precedentes en trabajos similares las encontramos en autores que han tenido interés en desarrollar los sentidos mediante el "arte", en esto incluimos música, artística y expresión corporal a partir de un entorno estético.

Abad hace referencia a citas de otros autores que afirman que (2008:131):

La palabra estética significa sentir y percibir mediante los sentidos o de la intuición sensible. Para los niños y niñas de la escuela Infantil la experiencia estética es una forma de comprender todas las imágenes del mundo y les proporciona las claves para interpretarlas y dotarlas de significado, el conocimiento es el que predomina en la primera infancia. La experiencia estética permite trabajar desde multiplicidad de campos emotivos que pueden impregnar los ámbitos y campos de actuación del conocimiento infantil y desde la multiplicidad de lenguajes que se pueden construir. El desarrollo del sentido estético es la síntesis entre el pensamiento, el sentimiento y la percepción que se manifiestan en el juego, en el arte y en la vida (Gennari 1997). 
Las instalaciones artísticas de este nuevo arte contemporáneo permiten un desarrollo integral del discente, ya que se trabaja tanto la educación cognitiva como la emocional, la educación en valores y el juego simbólico Pestalozzi (1827: 746; citado en Callejón Chinchilla y Yanes Córdoba, 2012:6) daba relevancia a los trabajos manuales y al desarrollo de los cinco sentidos a través de los entornos estéticos.

Hemos querido una vez fundamentado nuestro marco teórico verificar que con el arte podemos perfeccionar los cinco sentidos en niños y en niñas de entre tres y cuatro años de edad, porque esto es la base de los aprendizajes posteriores.

El arte sensorial se caracteriza por experimentar sensaciones variadas a través del oído, la vista, el tacto, el gusto y el olfato. Nos permite aprender y conocer el mundo que nos rodea a través de la percepción sensorial. Permite transformar las realidades gracias a la intervención de nuestros cinco sentidos.

Se ha puesto en marcha un protocolo de actuación etnográfico educativo basado en las artes, ya que las herramientas que darán la información que se busca es la propia actividad artística que ha sido a su vez el objeto de estudio. Entramos al aula para recoger y analizar las características, posibilidades y limitaciones del entorno para poder transformarlo en un mundo mágico y sensorial para los niños y las niñas.

Fue necesaria la observación directa durante distintos días a lo largo de tres meses antes de plantear nuestra "instalación artística”. La información extraída en estos días quedó anotada en un diario de trabajo que se consideró a la hora de diseñar nuestro entorno y darle un nombre, pues partimos de lo necesario e interesante para los protagonistas de este proyecto.
Esta investigación basada en las artes no es de acción y participación, pues nosotras solo hemos propuesto, diseñado y presentado el entorno adaptado a ellos, realmente los que participaron y actuaron fueron los escolares.

Los instrumentos o las técnicas empleadas en esta investigación son cualitativos, puesto que se valoran los resultados a través de la observación directa en el momento en el que los discentes interactúan con el entorno lúdico-estético y extraen conclusiones de ello a partir de las actividades artísticas propuestas. También se tuvieron en cuenta los dibujos realizados por los alumnos y por las alumnas después de la experiencia para intentar ver cómo recordaban lo vivido en primera persona.

\section{Objetivos de la investigación} basada en las artes.

1. Encontrar y verificar una nueva forma de trabajar mediante el aprendizaje por descubrimiento y significativo en las aulas de Infantil a través del arte.

2. Dar a conocer los procesos y resultados que se han observado durante y después de la puesta en práctica con las actividades artísticas.

3. Desarrollar y poner en práctica un modelo de instalación artística en las aulas de Infantil con el fin de conseguir los objetivos didácticos propuestos para esta etapa educativa, en concreto para desarrollar los cinco sentidos.

4. Posicionar el arte como un área crucial, necesaria e interdisciplinar para la Educación Infantil.

\section{Marco empírico.}

Como ya se ha comentado en la introducción el enfoque metodológico con el que se ha llevado a cabo esta investigación 
ha sido etnográfico educativo desde una perspectiva basada en las artes al que podríamos llamar "Investigación Educativa Basada en las Artes” (Marín y Roldan: 2014). En este apartado se incluyen los objetivos didácticos y el plan de trabajo junto con las fases desarrolladas a lo largo de este proyecto.

\section{Objetivos didácticos de la instalación} artística.

1. Utilizar los cinco sentidos para interpretar lo que hay en el espacio creado.

2. Conocer su cuerpo, así como algunas de sus virtudes y limitaciones.

3. Trabajar los saltos de manera intuitiva.

4. Afianzar los desplazamientos a cuadrupedia.

5. Reconocer los sonidos de su entorno (el otoño y el invierno)

6. Fomentar la intuición y la creatividad a través de la manipulación, la escucha activa de sonidos ofrecidos y el desarrollo de sus cinco sentidos.

7. Fomentar la socialización en el aula.

\section{Plan de trabajo para la investigación.}

El nuevo arte contemporáneo ha traído consigo grandes renovaciones que lo hacen una herramienta crucial dentro de las aulas, ya que permite que los procesos de enseñanza y de aprendizaje sean adecuados y positivos.

La base de esta investigación está en una trabajo universitario realizado durante la carrera que nos dio a conocer otra forma de trabajar en las aulas, apartada de las metodologías tradicionales y en la lectura de la tesis doctoral de uno de los promotores de las “instalaciones artísticas" llamado Abad (2008), pues este nos ofreció otra mirada hacia el arte.

A partir de esto hemos buscado artistas que ya han trabajado con ello y han obtenido resultados positivos. Lo primero que hemos hecho es formar nuestro marco teórico acerca del tema, nuestra primera fase de investigación ha sido una búsqueda detenida en diferentes fuentes que nos han dado conocimientos y herramientas para justificar nuestra posición sobre cómo se puede enseñar en las aulas. Después de estructurar nuestros fundamentos teóricos hemos recurrido a la Normativa Vigente para ver qué lugar ocupa el arte y cómo se propone que se integre en el currículo de Infantil.

Atendiendo a la a la ORDEN ECI/3960/2007, de 19 de diciembre, por la que se establece el currículo y se regula la ordenación de la educación infantil y en el REAL DECRETO 1630/2006, el arte se incluye en unas de las áreas de conocimiento llamada Lenguajes: Comunicación y representación.

Aquí el arte se debe emplear para desarrollar los contenidos didácticos relacionados con la percepción sensorial, los lenguajes artísticos para el desarrollo de la creatividad y la imaginación y como una forma de comunicación. Con la creación de las instalaciones artísticas no solo tratamos esta área sino que también trabajamos aspectos de las otras dos como son: Conocimiento de sí mismo y autonomía personal y Conocimiento del entorno. Se tratan los contenidos de manera insterdisciplinar. Uno de los contenidos que se deben de trabajar en esta etapa son los cinco sentidos y por ello nuestra instalación artística será creada con el objetivo de abordar este asunto.

La segunda fase es crucial para esta investigación ha consistido en observar el día a día de unos niños y unas niñas de Educación Infantil junto con su profesora para ver las necesidades e intereses de estos, además hemos tomado en cuenta el espacio que contamos para la puesta en práctica, así como su mobiliario, sus medidas, la posibilidad que nos ofrece y las limitaciones. 
Hemos formado parte del aula en distintas ocasiones durante tres meses mientras íbamos creando nuestro marco teórico y construyendo el proyecto en el cual fundamentamos y explicamos lo que queremos trabajar, cómo, por qué, con qué recursos y con qué finalidad. Este proyecto ha ido modificándose según lo observado cada día y lo anotado en el diario de trabajo.

La tercera fase ha sido el proceso de preparación de la "instalación artística" elaborada por nosotras cinco a lo largo de bastantes semanas, pues además de preparar el entorno estético y lúdico hemos elaborado los recursos y materiales físicos y sonoros necesarios para alcanzar los objetivos didácticos y por supuesto los de esta investigación.

La cuarta fase ha sido la puesta en práctica de nuestra "instalación artística" para verificar si se consiguen los objetivos didácticos que nos propusimos y si efectivamente el arte ha contribuido a ello, siendo la herramienta necesaria para llegar a los fines. La observación directa y los dibujos de los discentes después de la experiencia serán los instrumentos para evaluar el trabajo realizado.

\section{Fase 1: Fundamentación teórica.}

Las nuevas perspectivas del arte contemporáneo adaptado a las necesidades e intereses de la sociedad y en especial de los sistemas educativos están haciendo que cada vez más el arte deba de ser una herramienta crucial para los aprendizajes significativos y por descubrimiento dentro de las aulas.

Son muchos los artistas que enseñan cómo crear arte para trabajar en las aulas contenidos de las diferentes áreas de conocimiento, de forma que de manera interdisciplinar podamos hacer que la escuela se convierta no solo para los niños y para las niñas, sino también para sus familiares y maestros o maestras en el lugar preferido e idóneo para aprender conocimientos, habilidades, actitudes y valores.

El arte es muy poderoso en este aspecto y las propuestas de Abad (2008) entre otras que hablan de un nuevo concepto denominado "instalaciones artísticas” deben incluirse como metodologías educativas activas. Este tema se está dando a conocer en la actualidad y está cambiando el pensamiento de muchos docentes.

Nuestras referencias y precedentes en trabajos similares los encontramos en autores que han tenido interés en trabajar los sentidos a través del "arte”, en esto incluimos música, artística y expresión corporal a partir de un entorno estético y lúdico. Abad (2008) hace referencia a citas de otros autores que también apuestan por ello.

Las instalaciones artísticas de este nuevo arte contemporáneo permiten un desarrollo integral del alumnado, ya que se trabaja tanto la educación cognitiva como la emocional, la educación en valores y el juego simbólico.

Hoy en día podemos encontrar artistas, grupos de especialistas y docentes en centros educativos que trabajan los cinco sentidos a través del arte. El arte sensorial se caracteriza por experimentar sensaciones variadas a través del oído, la vista, el tacto, el gusto y el olfato. Nos permite aprender y conocer el mundo que nos rodea a través de la percepción sensorial.

El arte sensorial, permite transformar las realidades gracias a la intervención de nuestros cinco sentidos. Siempre que planteamos un trabajo dentro de las instalaciones artísticas ponemos a los niños y a las niñas en situación de aprender mediante el descubrimiento, la 
experimentación, la intuición y la creatividad.

Este aspecto educativo de la educación artística en el que participan la inteligencia, la imaginación, el ingenio, la diversidad de opciones, el distinto uso y manipulación del material, etc., no debemos olvidarlo nunca, dando al proceso de creación artística el justo valor formativo.

También nuestro rol de docente implica crearlos para que los pequeños lo vean como un entorno estético y lúdico en el que elegirán y manipularán diferentes objetos, texturas de varios colores y dejaremos volar su imaginación para que interaccionen con él.

Destacar a Gardner (citado en Marie Shannon, 2013) y su teoría de las inteligencias múltiples, ya que pretendemos trabajar de manera global estas inteligencias que tenemos cada uno de nosotros aunque destaquemos en algunas de ellas más que en otras. Estas son: la inteligencia lingüística-verbal, la inteligencia física-cinestésica, la inteligencia lógica-matemática, la inteligencia espacial, la inteligencia musical, la inteligencia interpersonal, la inteligencia intrapersonal, la inteligencia naturalista.
Las instalaciones artísticas por su concepto de globalidad son imprescindibles para desarrollar cada una de estas inteligencias y en la puesta en prácticas se verá claramente cómo se consigue el trabajo integrado de todas estas inteligencias o de la mayoría de estas.

Pestalozzi (1827: 746; citado en Callejón Chinchilla y Yanes Córdoba, 2012:6) daba relevancia a los trabajos manuales y al desarrollo de los cinco sentidos a través de los entornos estéticos. Del él cogemos la idea de entorno estético y los trabajos manuales con el mural.

De los movimientos Land - Art (citado en Abad, 2008: 316) recogemos el trabajo con el entorno natural. Para los olores emplearemos esencias de plantas y de flores entre otras cosas. Vamos a diseñar mandalas de formas circulares con diferentes texturas como: flores, plantas, tierra, piedrecitas etc.

La palabra "mandala”, en sánscrito, se traduce como círculo. A través de un dibujo efímero expresamos nuestra propia naturaleza y creatividad. Andy Goldsworthy ha trabajado con ello (citado en Abad, 2008: 316). Abad (2008: 315-316) muestra fotografías realizadas por él mismo que ejemplifican muy bien lo que puede ser una mandala realizada por niños:
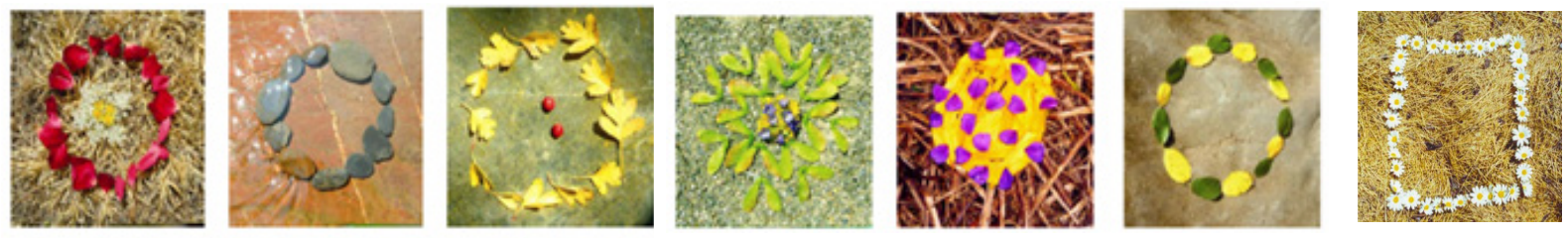

Imagen extraída de Andy Goldsworthy. Mandalas Naturales

http://www.oei.es/educacionartistica/primerainfancia/documentacion_artistas.php (En OEI: http://www.oei.es/) 


\section{Tercio Creciente}

DOI: $10.17561 /$ rtc.n12.8

Investigación

De Andy Goldsworthy se puede resaltar que está interesado en reflejar los procesos temporales en sus obras efímeras y las texturas con diferentes formas de los elementos naturales en sus mandalas (realizadas con hojas, barro, nieve, agua, arena, etc.)Esto es muy interesante para mostrar la desaparición.
Revista de Estudios en Sociedad, Artes y Gestión Cultural

http://revistaselectronicas.ujaen.es/index.php/RTC/index www.terciocreciente.com
Los niños y niñas se divierten y aprenden mientras realizan composiciones con los elementos que nos ofrecen la naturaleza al igual que lo hacen los artistas del movimiento de Land-Art, así también desarrollan los sentidos y su creatividad. De este autor destacamos las siguientes fotografías:
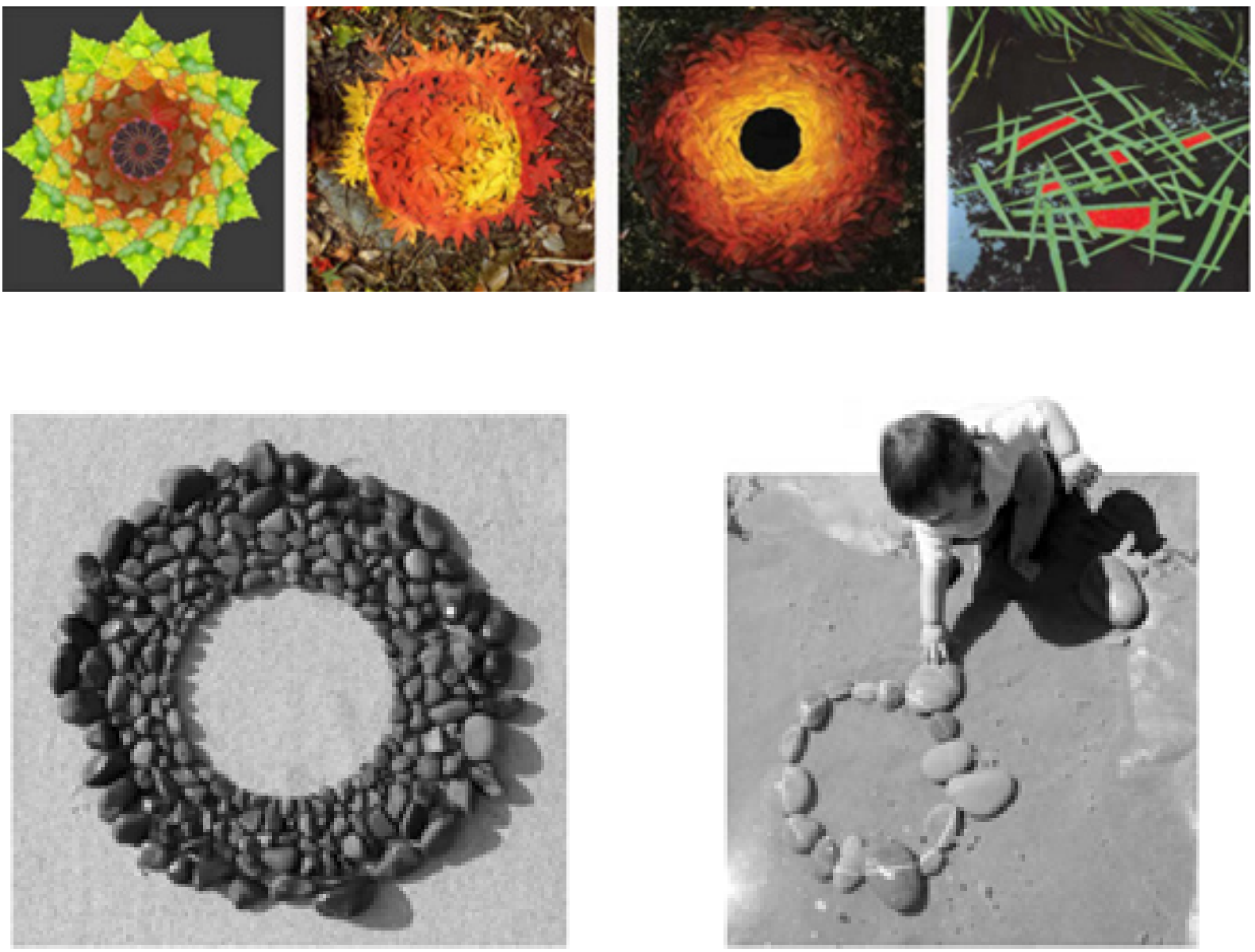

Imagen extraída de Andy Goldsworthy. Mandalas Naturales

http://www.oei.es/educacionartistica/primerainfancia/documentacion_artistas.php (En OEI: http://www.oei.es/) 


\section{Tercio Creciente}

DOI: $10.17561 /$ rtc.n12.8

Investigación

Díaz-Obregón (2003: 126; citado en Abad, 2008: 320) apunta que:

En la instalación se aprecia una relación significativa de la multiplicidad, la multisensorialidad, el carácter contextual, la variedad de significados y la democratización culturas de la instalación con los aspectos postmodernos de la educación artística.

Nosotras hemos diseñado diferentes elementos sensoriales y además hemos ambientado el entorno con diferentes colores
Revista de Estudios en Sociedad, Artes y Gestión Cultural

http://revistaselectronicas.ujaen.es/index.php/RTC/index www.terciocreciente.com y sonidos para una percepción multisensorial como afirma Díaz-Obregón.

Para nuestro proyecto hemos escogido una idea de Abad (2008) que nos parece interesante, vamos a realizar un gran caracol de hojas secas para que los niños recorran el camino y perciban así un espacio junto al sonido de las hojas del otoño y del paisaje sonoro, ya que en el ambiente sonoro apreciarán entre otras cosas el sonido de las hojas en el otoño o la lluvia y el viento en el invierno. Por ejemplo:
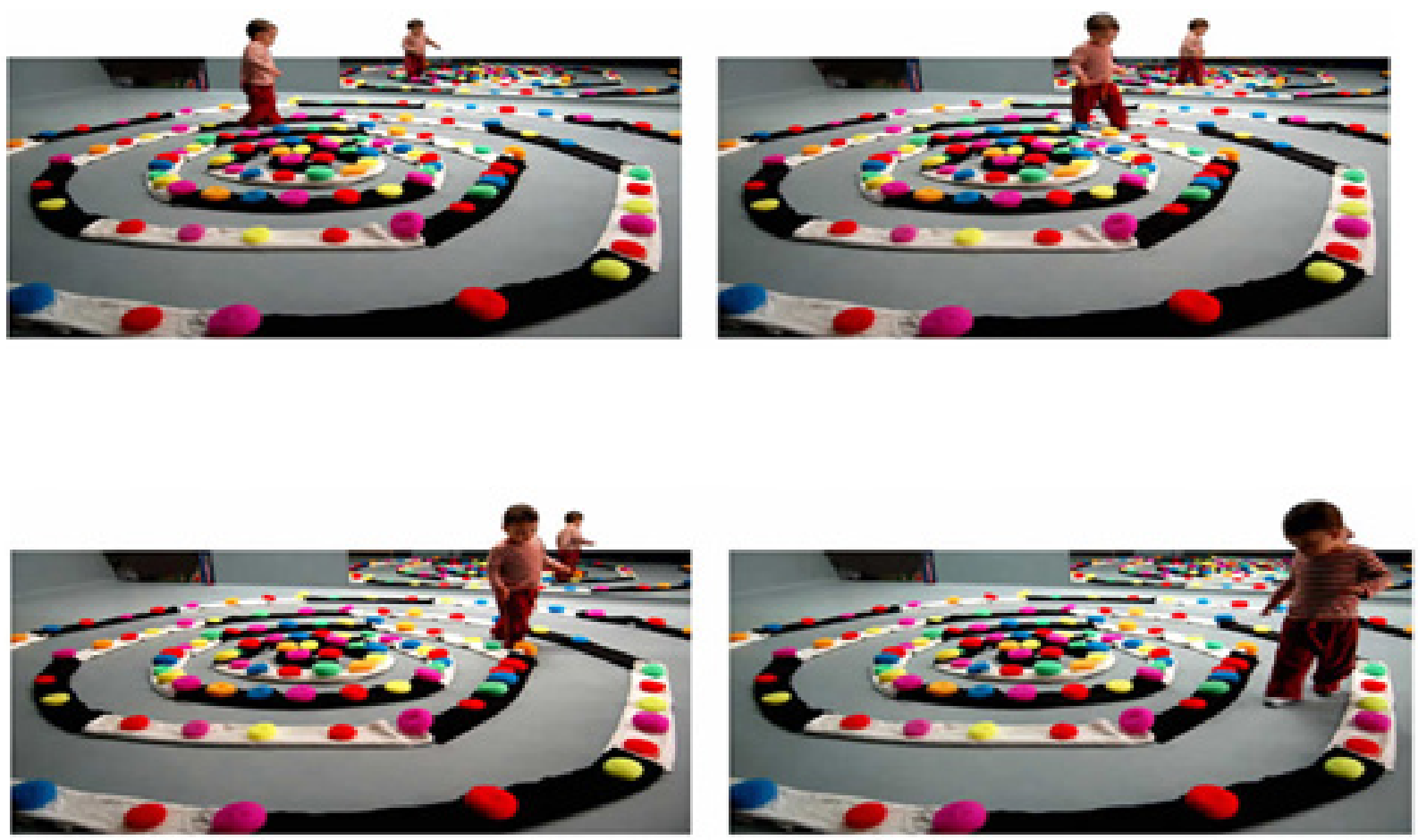

Imagen extraída de: Abad, Javier. Espiral.

http://www.oei.es/educacionartistica/primerainfancia/documentacion_artistas.php 
Hemos considerado la idea de instalación artística de YAYOI KUSAMA con su obra Obliteration Room. Mostramos la imagen de la que partimos:
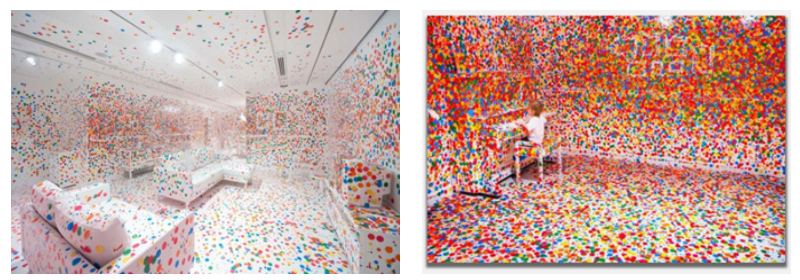

Imágenes extraídas de: KUSAMA, YAYOI. THE OBLITERATION ROOM

interactive.qag.qld.ooknowseeforever/works/obliteration_room/

Esta autora transforma los espacios con puntos de colores que contrastan y hacen que el entorno se llene de color y de cabida a la imaginación en él. Otro innovador en instalaciones artísticas es Daniel Buren con sus ventanas iluminadas consigue efectos luminosos atrayentes que despierten sensaciones visuales a tractivas. Mostramos la imagen de la que partimos:

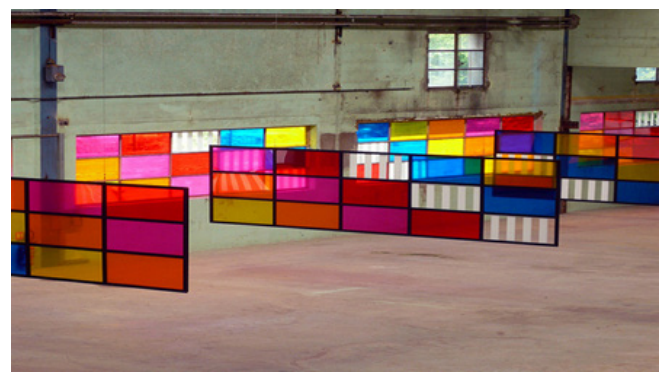

imagen extraída de: Buren, Daniel. Una de sus obras. https://www.flickr.com/photos/commentdire
Otros artistas de este nuevo arte son Jordi Ferreiro y Víctor Ramírez que trabajan con instalaciones artísticas formadas con una lluvia de confeti de papelitos de colores. Una de sus obras en la cual nos inspiramos es:
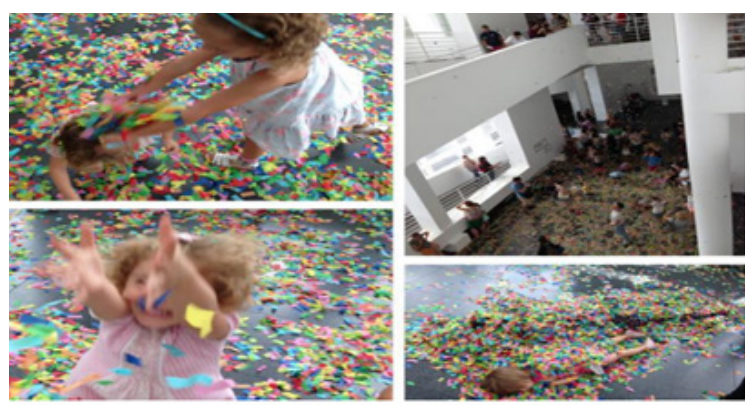

Imagen extraída de: Ferreiro y Ramírez. Lluvia de confeti. . http://es.paperblog.com/macba-arte-contemporaneo-para-ninos-

Estos autores ya han comprobado que es eficaz trabajar con ello en el ámbito educativo. Además hemos tenido que buscar otros autores que han trabajado la música y las artes plásticas para poder crear los objetos sonoros y manipulativos que se emplean dentro de estos entornos por ejemplo, en nuestro trabajo nos hemos basado en los siguientes:

PEDAGOGIA REGGIANA: la educación en Reggio Emilia, partía de los objetivos concretos a desarrollar y los conciliaba con las particularidades: la organización del ambiente de trabajo armonioso. Espacio dedicado a la improvisación creativa. (Abad: 2008).

LORIS MALAGUZZI: relaciona el ambiente estético, el desarrollo de los 
afectos, el placer, la realidad ambiental, con la competencia comunicativa con la transformación de la escuela, etc. (Abad: 2008).

MURRAY SCHAFER: de este vamos a emplear su idea de PAISAJE SONORO (soundscape) al que define como "el ambiente sonoro que se crea en determinados lugares.”

CARL ORFF: Orff apostaba por estudiar la música de forma grupal y cooperativa. Improvisación instrumental.

SRIABIN: SINESTESIA. "Relacionar colores con los sonidos". Para el ambiente de la instalación artística.

\section{Fase 2: Observación en el aula}

\section{Características del centro observado}

El centro educativo se llama Niña María, se encuentra en Linares (Jaén). La información ha sido extraída del Plan de Centro presente en su blog y del director del centro. Esta escuela se encuentra situada en el extrarradio de Linares (Jaén) en una zona de acción educativa preferente que no goza de ningún prestigio por ser un barrio humilde tanto en el plano económico como socio-cultural.

La economía familiar es baja y hay muchas familias en pobreza y sin trabajo. Es un edificio de dos plantas, con rampas de acceso a la planta de arriba y con escaleras de acceso a la misma planta. Cuentan con un patio separado por dos partes (pista deportiva y los olivos). Consta de:

- PRIMERA PLANTA: tres aulas, un aula de usos múltiples, un aula de comedor, tres aseos y un cuarto de limpieza.
- SEGUNDA PLANTA: seis aulas de uso docente, una sala de profesores, un despacho, un aseo de profesorado, tres aseos de alumnado, un cuarto de limpieza y una sala destinada al AMPA.

El aula tiene unas dimensiones amplias y nos permite trabajar sin problema en la elaboración de este proyecto, el mobiliario es movible y los elementos se pueden cambiar de lugar sin dificultad. Era la siguiente:

\section{Observaciones dentro del aula}

Esta investigación se ha llevado cabo con el permiso de la directora del centro y de la tutora de los niños y de las niñas con los que vamos a trabajar junto con la Junta de Andalucía. Le comentamos nuestros objetivos y le presentamos un esquema de nuestro proyecto para que apoyaran nuestra decisión y nos permitieran hacerlo.

Tanto la directora como la maestra nos recibieron cordialmente y se prestaron a colaborar en dicha investigación que culminará con los resultados obtenidos tras la puesta en práctica en el aula.

Nos encontramos con niños y niñas de entre tres y cuatro años que se encuentran en el segundo ciclo de la etapa de Educación Infantil. Estos niños y niñas llegan a una escuela por primera vez y aún se están adaptando al entorno educativo.

Después de observar el aula y los comportamientos de los protagonistas durante los meses de octubre, noviembre y diciembre nos pusimos a diseñar y a crear los recursos necesarios. 
Tercio Creciente

DOI: $10.17561 /$ rtc.n12.8

Investigación
Revista de Estudios en Sociedad, Artes y Gestión Cultural

http://revistaselectronicas.ujaen.es/index.php/RTC/index www.terciocreciente.com

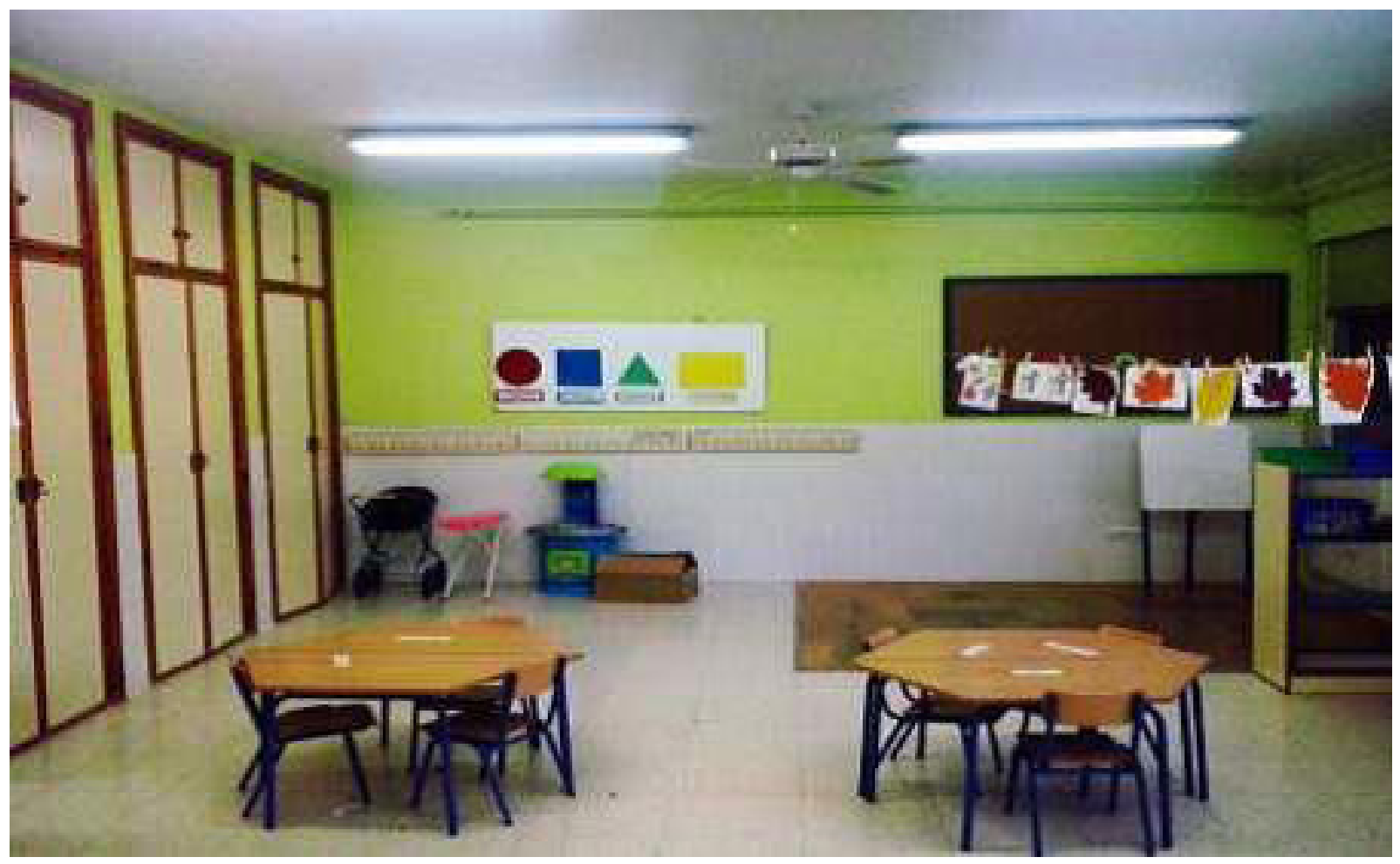

Fotografía del aula realizada por la autora y sus colaboradoras 


\section{Fase 3: Proceso de preparación de la instalación y materiales.}

Este proyecto se llama Un Paseo Sensorial Por el Arco Iris, es así porque dicha instalación permitirá el desarrollo de los cinco sentidos y además emplearemos los siete colores del arco Iris.

Los materiales y recursos empleados son:

Tabla 1. Materiales y recursos para la instalación artística.

\begin{tabular}{|l|l|l|l|l|l|l|}
\hline $\begin{array}{l}\text { Papel pinocho } \\
\text { de 7 colores }\end{array}$ & $\begin{array}{l}\text { Cartulinas de } \\
\text { colores }\end{array}$ & Lana de colores & Tijeras & $\begin{array}{l}\text { Globos de } \\
\text { colores }\end{array}$ & $\begin{array}{l}\text { Gomas elásticas } \\
\text { y cuerdas }\end{array}$ & $\begin{array}{l}\text { Ceras de co- } \\
\text { lores duras y } \\
\text { blandas }\end{array}$ \\
\hline $\begin{array}{l}\text { Papel gelatina } \\
\text { de 7 colores }\end{array}$ & Cartones & $\begin{array}{l}\text { Plásticos o } \\
\text { bolsas }\end{array}$ & Pegamento & $\begin{array}{l}\text { Papelitos de } \\
\text { colores y ser- } \\
\text { pentinas }\end{array}$ & $\begin{array}{l}\text { Temperas y } \\
\text { pinceles }\end{array}$ & Rotuladores \\
\hline $\begin{array}{l}\text { Cinta de rega- } \\
\text { lo de 7 colores }\end{array}$ & Hojas secas & $\begin{array}{l}\text { Papel continuo } \\
\text { blanco y de 7 } \\
\text { colores }\end{array}$ & Cola & Tres mesas & Papel de cocina & $\begin{array}{l}\text { Lápices, borra- } \\
\text { dores y saca- } \\
\text { puntas }\end{array}$ \\
\hline $\begin{array}{l}\text { AUDACITY } \\
\text { paisaje so- } \\
\text { noro }\end{array}$ & $\begin{array}{l}\text { Platitos y } \\
\text { bandeja de } \\
\text { plástico }\end{array}$ & Purpurina & Periódicos & Fiso & Escalera & Reglas \\
\hline $\begin{array}{l}\text { Una sábana } \\
\text { blanca }\end{array}$ & Rama de olivo & Cinta aislante & $\begin{array}{l}\text { Pegatinas } \\
\text { de colores }\end{array}$ & Chinchetas & $\begin{array}{l}\text { Folios de co- } \\
\text { lores }\end{array}$ & $\begin{array}{l}\text { Cámara de fo- } \\
\text { tos y de vídeo }\end{array}$ \\
\hline
\end{tabular}

Después de dejar la clase vacía y montar nuestra instalación, el aula quedó repartida de la siguiente manera: la pared decorada con los distintos colores del arco Iris, varias mesas con los distintos sentidos (tacto, gusto y olfato), una cuerda con globos colgando para invitarles a saltar, dos túneles que daban acceso a la instalación, papel continuo blanco en el suelo con ceras repartidas para que los niños y las niñas pintaran en él tal como quisieran.

Varias mandalas con diferentes texturas pegadas por las paredes, instrumentos sonoros como palos de lluvia, maracas, sonajeros, guitarras, relojes de arena para la percepción del tiempo repartidos por el suelo, en una parte de clase hojas esparcidas en forma de caracol para que pasen alrededor del camino mientras descubren objetos sonoros en su camino muy variados y un túnel en mitad de la instalación artística con globos dentro para que los niños y las niñas pudieran entrar y salir.

Otros dos túneles que les permitían entran en el entorno, mientras traspasaban los túneles miraban por las ventanas de colores que cambiada la iluminación del entorno y además los túneles tenían un suelo espacial, ya que, cada uno de ellos tenía una textura con plásticos de burbuja, sin burbuja, de hojas secas, etc.

Echamos confetis de papeles de colores por el suelo. Por último, dimos a reproducir el paisaje sonoro que fue muy adecuado para que los niños y las niñas accedieran a la instalación artística y se familiarizaran con algunos sonidos de la naturaleza como pajaritos, viento, sonido de las hojas de los árboles, etc. 

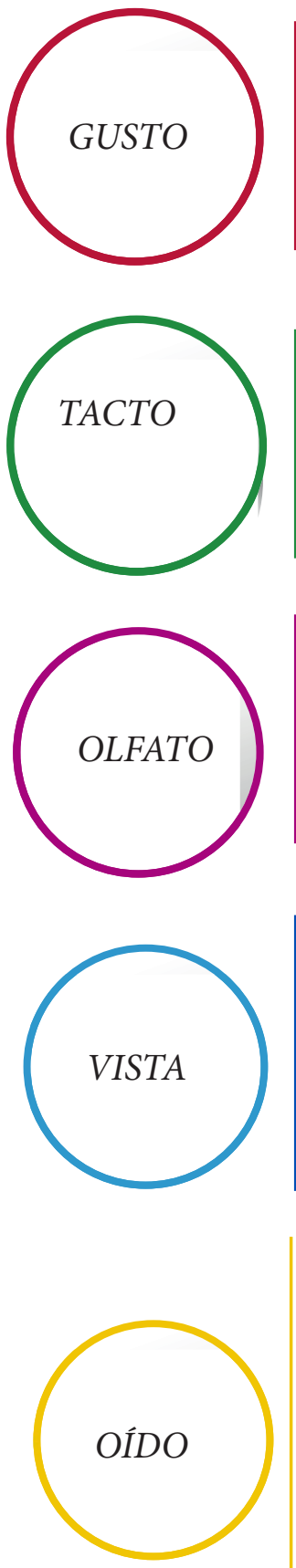

Frutas

Chocolate

Galletas

Materiales: bandeja y comida

Mandalas creativas

Papel de periódico

Cajitas con harina, especias, cola-cao, azúcar

Materiales: trozos de texturas, algodón, papel de periódico, plantas, telas, legumbres, conchas de almejas, pajitas, arena, ect. .

Platitos con especias y hierbas (romero, tomillo, laurel, anís molido)

Ambientadores escondidos (solo para que identifiquen olores) Materiales: especias y hierbas y ambientadores.

\section{Relojes de arena}

Diferentes texturas de colores variados

Globos de colores con purpurina

Papelitos, papel pinocho, papel gelatina y papel de colores

Serpentinas, lazos

Cartulinas de colores

Mandalas creativas

\section{Maracas}

Palos de lluvia

Sonajeros de nueces

Guitarras de cartón con gomas elásticas

Sonajeros con tapones de las botellas de agua

Paisajes sonoros. AUDACITY.(Dibujan en un mural con ceras

blandas según sus percepciones sensoriales).

Materiales: botellas de plástico, globos, arroz y legumbres,

chapas, piedrecitas y arena, cáscaras de nueces, tapones,ect. 
Tercio Creciente

DOI: $10.17561 /$ rtc.n12.8

Investigación

En las imágenes que mostramos se aprecian los resultados de la "instalación artística" dentro del aula y los recursos
Revista de Estudios en Sociedad, Artes y Gestión Cultural

http://revistaselectronicas.ujaen.es/index.php/RTC/index www.terciocreciente.com visuales, creativos y sonoros que se han utilizado para esta investigación:
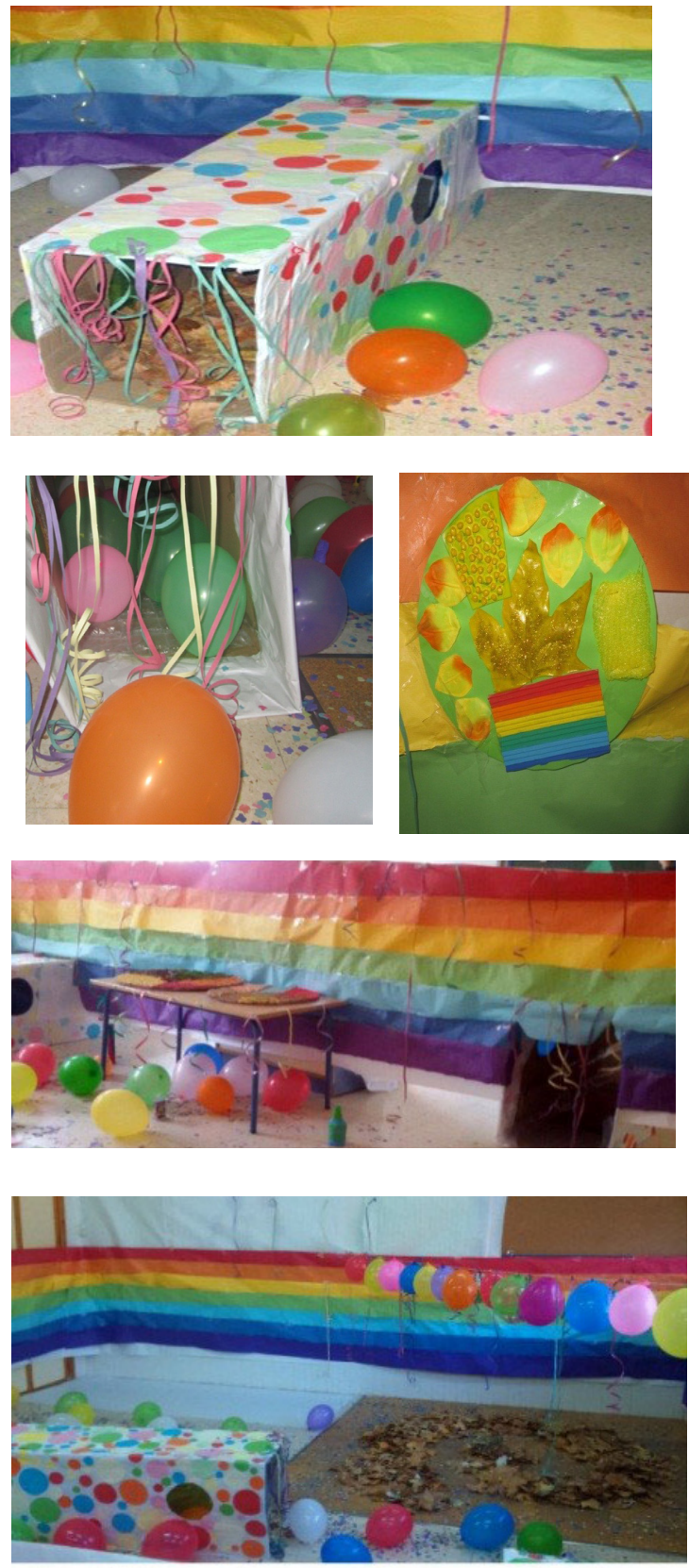
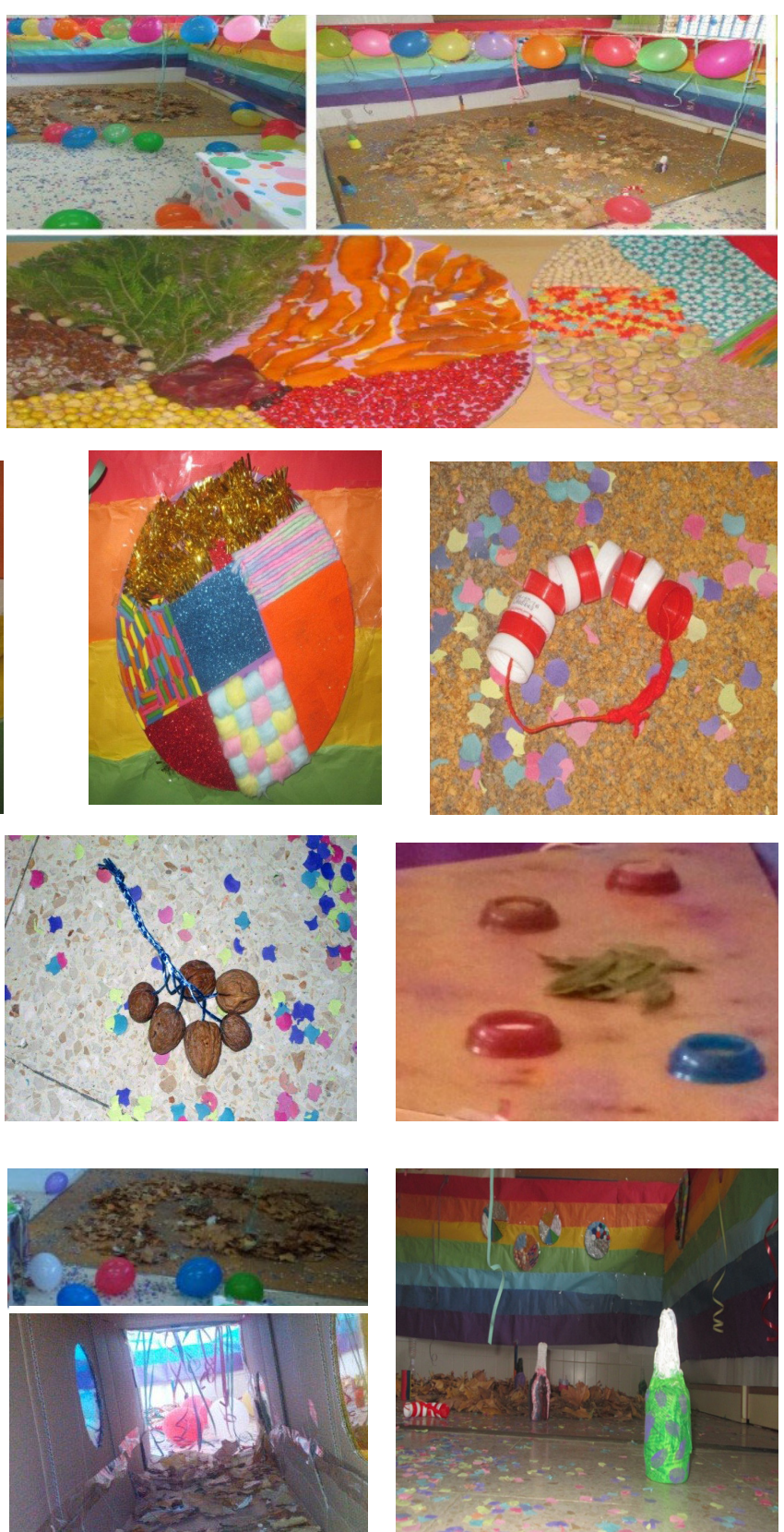


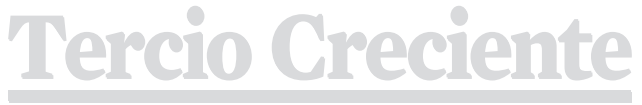

DOI: $10.17561 /$ rtc.n12.8

Investigación

Este proyecto tuvo lugar el viernes 11 de diciembre de 2015, los niños y las niñas no sabían nada, el día anterior estuvimos montando la instalación, por este motivo los niños y las niñas dieron sus clases en un aula diferente. El viernes llegó el gran día.

Los niños y las niñas se encontraron con una gran sorpresa, a partir de ahí, ellos
Revista de Estudios en Sociedad, Artes y Gestión Cultural

http://revistaselectronicas.ujaen.es/index.php/RTC/index www.terciocreciente.com mismos interactuaron con el entorno y desarrollaron sus conocimientos a la vez que empleaban sus cinco sentidos. Nuestro papel era simplemente fotografiar los momentos, grabarlos a la vez que observábamos lo que ocurría y anotábamos lo más relevante.

A continuación se muestran las fotografías sacadas por la autora y sus colaboradoras:
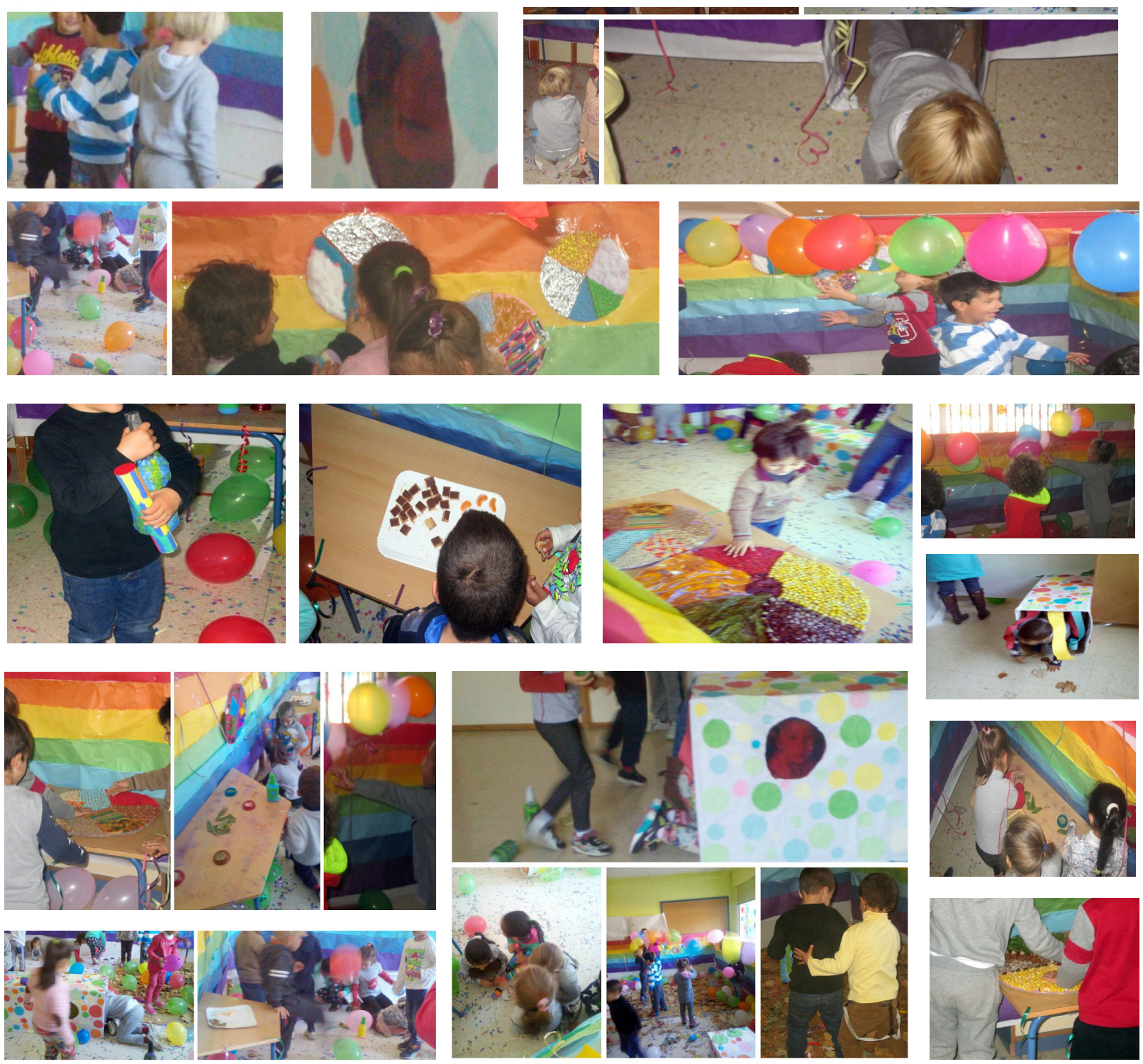
Tercio Creciente

DOI: $10.17561 /$ rtc.n12.8

Investigación
Revista de Estudios en Sociedad, Artes y Gestión Cultural

http://revistaselectronicas.ujaen.es/index.php/RTC/index www.terciocreciente.com

Dibujos de los niños y de las niñas después de la experiencia.
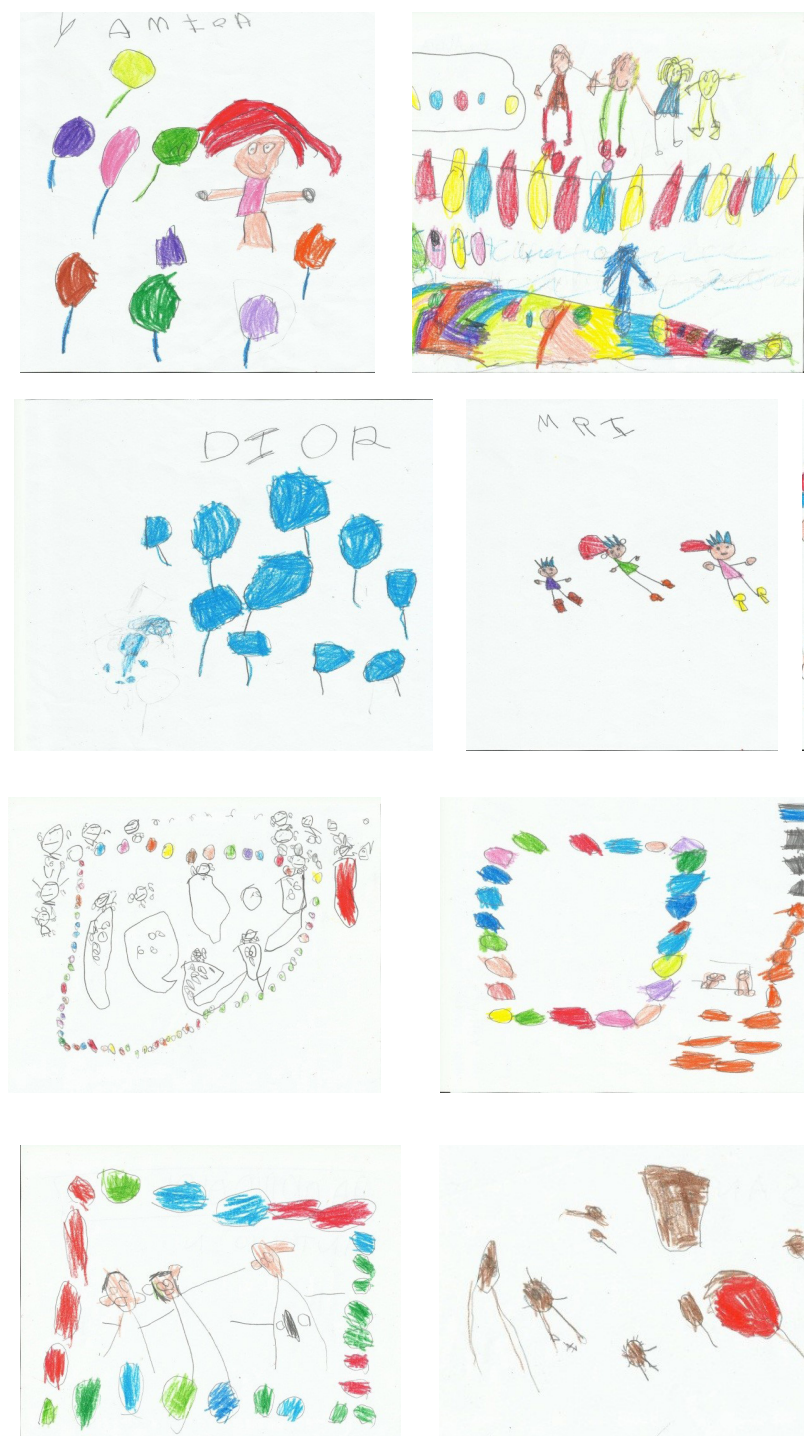

Estos dibujos demuestran que después de la experiencia los niños y las niñas recuerdan aquellas cosas que les llaman la atención, que les motivan y que les permiten estar activos y formar parte de sus procesos de enseñanza y de aprendizaje. Cada alumno y alumna ha reflejado aquello que más les ha gustado y
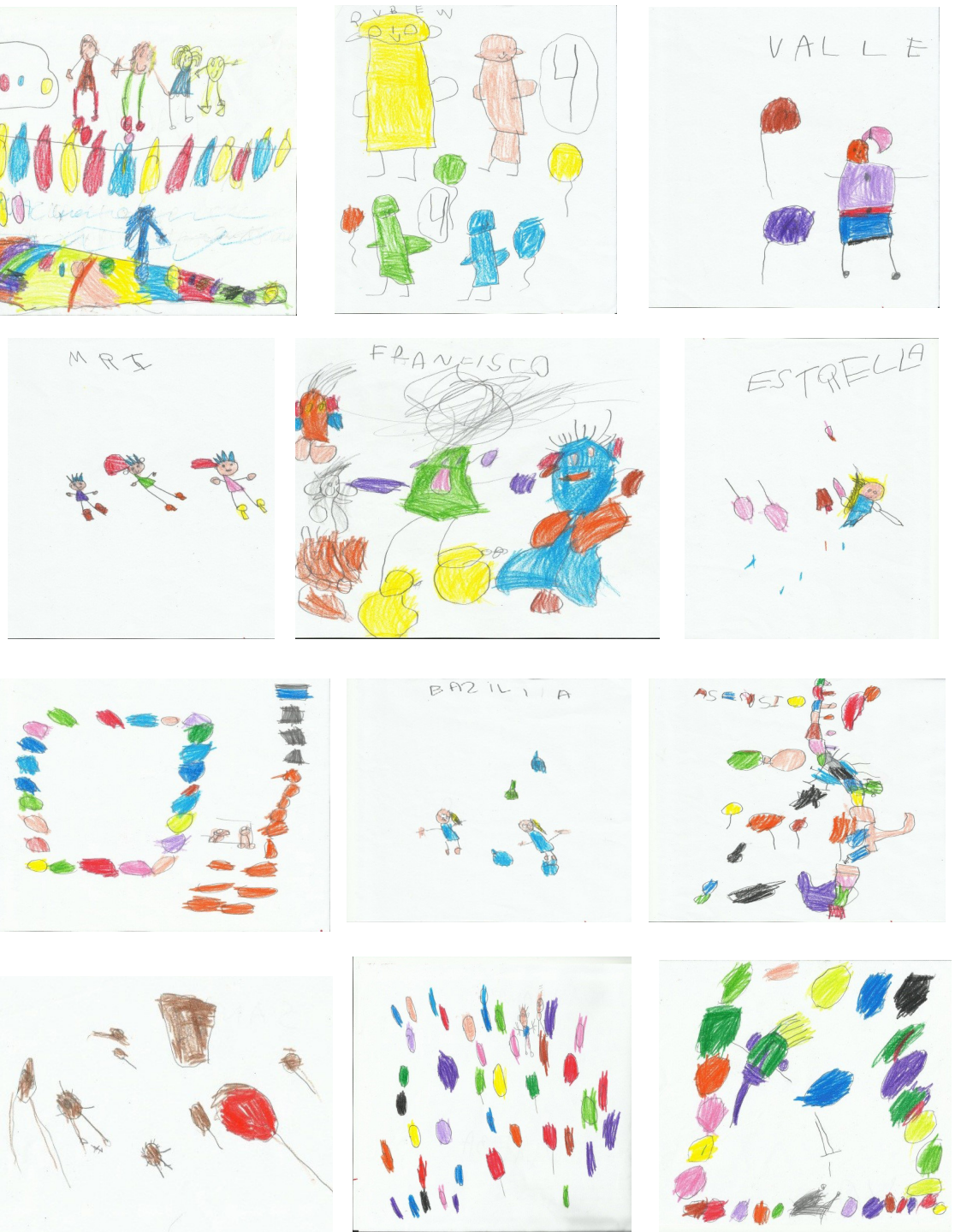

cuando le preguntamos por la experiencia recordaban con cariño y una sonrisa lo sucedido, así lo reflejan también en sus dibujos posteriores. Los colores empleados en la "instalación artística" se ven perfectamente en muchos de los dibujos, además los objetos sonoros, los globos, los túneles y las mandalas. 


\section{Resultados de la investigación}

\section{Observaciones durante la puesta en práctica.}

Los niños al entrar tuvieron una reacción de sorpresa y a la vez de temor porque no sabían cómo empezar y por donde acceder al espacio. Uno de ellos se da cuenta que solo existe una manera de acceder y es entrar a través del túnel, después todos le siguen. Aquí vemos que lo nuevo les llama la atención y que por sí mismos pueden acceder al espacio y experimentar con él.

Pronto empezaron a jugar con los globos, las maracas y demás instrumentos que estaban repartidos por la instalación. Así empezaron a sentir diferentes emociones y sensaciones. Comenzó el trabajo con sus sentidos.

Repetían con los objetos y empezaban a imaginar mundos, recordar experiencias, sonidos de su entorno, etc. En esta ocasión la imaginación y la creatividad comenzaban a ponerse en funcionamiento.

En el mural blanco que se les pegó en el suelo dibujaron todo aquello que pasaba por sus “cabecitas pensantes". El lugar era un Arco Iris y así lo reflejaron en sus dibujos llenos de color, el sonido representaba el otoño y el invierno y pintaron hojas, árboles, el viento, etc. En ese momento vimos que nuestro trabajo estaba dando frutos y todo iba perfectamente.

Las hojas del caracol después de recorrer el camino las tiraron hacia el techo para cogerlas y jugar con ellas. Pero lo interesante es que antes de que hicieran esto, cada uno de los niños y de las niñas caminaron en forma de espiral desde principio a fin, sin salirse del camino, adaptándose al espacio y sin instrucciones por sí mismos. También se ayudaban mutuamente para llegar a la meta sin perderse.
Se dieron cuenta que en los túneles podían mirar por las ventanas y ver su "clase" de muchos colores que les recordaban al sol, al campo, al invierno, al fuego, etc. No dejaban de atravesarlos para sentir sus maravillosas y diferentes texturas que les encantaban.

Saltaron, golpearon e intentaron coger los globos que hay en la cuerda a una altura accesible a ellos solo mediante el salto. De esta manera conseguimos los objetivos motrices y de educación física propuestos.

A uno de ellos se le ocurrió explotar los globos del suelo, los demás les siguieron. Así vimos que los niños son ocurrentes y pueden por sí mismos transformar de nuevo el espacio y cambiar nuestros planes previos. Pues no planeamos que los explotaran y además con diferentes partes de su cuerpo, conociendo así algunos de los límites y posibilidades que les ofrecen las diferentes partes de su cuerpecillo.

Un niño empezó a percutir con las cuerdas de una guitarrita y a cantar al mismo tiempo una canción muy flamenquita. De esta manera podemos afirmar que una simple cajita de cartón con gomas elásticas puede servir de guitarra para un alumno que ama la música.

Un alumno se pasó los 2 minutos que tarda la arena del reloj en caer mirando cómo pasaba el tiempo e incluso lo vimos que comenzaba a contar de forma oral los números que ya había aprendido en clase. Puede que la bajada de la arena le recordara el proceso del "conteo".

Las nueces se convirtieron en cascabeles navideños, pues les recordaban a la Navidad y los tapones eran sonajeros de bebés. Todos los agitaban con fuerza para escuchar sus sonidos. 
Una niña cogió una pelota hecha con capas de globos de colores que envuelven a su vez un globito de agua. Como era de color blanco, fue diciendo que en sus manos tenía un huevo cocido como el que hacía su mamá. Fue corriendo a decírselo a sus compañeras y se les ocurrieron ponerse a cocinar con los condimentos de olores naturales y el supuesto "huevo cocido". Otra vez vemos que ellos imaginan un mundo y transforman todo lo que hay a su alrededor.

Con las mandalas hechas con elementos naturales ocurrieron hechos muy curiosos, pues al acariciar las texturas te decían que eran: suaves, ásperos, gordos o finos e incluyo te aclaraban a lo que les llevaban cada una de ellas: playas, flores del campo, la tela de un vestido, la piel de las frutas, etc. Este invento es fabuloso para trabajar con los niños de Educación infantil.

La bandeja de comida desapareció de momento, pues el chocolate y las mandarinas les encantaban. Pudimos ver la reacción de sus caras en el chocolate (dulce) y las mandarinas (un sabor agrío), con estas últimas algunos de ellos hacían guiños, en cambio con el chocolate se relamían con su lengua.

Los cacharritos con las especias para oler les sirvieron para sus cocinitas, pues les recordaban a la comida que les hacían sus mamás. Era emocionante ver cómo interactuaban con el entorno lúdico y estético.

El desarrollo de la audición se produjo gracias a la gran variedad de instrumentos sonoros que ellos mismos podían agitar y hacer sonar como maracas, sonajeros, palos de lluvia, globos sonoros, etc. Al mismo tiempo bailaban, cantaban y se divertían todos juntos. Además el paisaje sonoro realizado con el viento, el movimiento de las ramas de los árboles y de las hojas, etc., fue ideal para el entorno.

Pudimos ver cómo entre ellos se socializaban al ayudarse los unos a los otros, abrazarse, dibujar juntos, contar sus experiencias y compartir los objetos y la comida. En sus caras pudimos apreciar su felicidad y su gran compenetración en el juego. Por este motivo, estas prácticas son útiles para fomentar la participación, la cooperación y la empatía en los niños y en las niñas de infantil. 
Tabla 2. Plantilla de los objetivos propuestos

\begin{tabular}{|c|c|c|}
\hline OBJETIVOS ESPECÍFICOS & $\begin{array}{l}\text { LO HAN } \\
\text { COSEGUIDO }\end{array}$ & $\begin{array}{l}\text { NO LO HAN } \\
\text { CONSEGUIDO }\end{array}$ \\
\hline $\begin{array}{l}\text { Descubrir y utilizar los cinco sentidos para interpretar } \\
\text { la realidad de sus entornos. }\end{array}$ & SI & \\
\hline Conocer su cuerpo, así como sus virtudes y limitaciones. & SI & \\
\hline Explorar y manipular lo que hay en su entorno. & SI & \\
\hline $\begin{array}{l}\text { Afianzar la percepción corporal, espacial, temporal y } \\
\text { sensorial de los discentes. }\end{array}$ & SI & \\
\hline Trabajar los saltos de manera intuitiva. & SI & \\
\hline Afianzar los desplazamientos a cuadrupedia. & SI & \\
\hline Apreciar y reconocer los sonidos que les ofrece su entorno. & SI & \\
\hline $\begin{array}{l}\text { Fomentar la intuición y la creatividad para explorar su } \\
\text { mundo y expresarse. }\end{array}$ & SI & \\
\hline $\begin{array}{l}\text { Comenzar a distinguir sus gustos y preferencias a } \\
\text { través de los sentidos. }\end{array}$ & SI & \\
\hline Fomentar la socialización en el aula. & SI & \\
\hline
\end{tabular}

\section{Otras sugerencias}

Los niños y las niñas han dibujado según lo que el ambiente sonoro les transmitían.

Han explotado todos los globos con las diferentes partes de su cuerpo.

Además han dado nombre a los objetos sonoros y les han dado utilidad musical. También los han asociado a su vida cotidiana.

Los niños y las niñas han compartido su espacio y los objetos sonoros.

Los niños y las niñas han golpeado con diferentes partes de su cuerpo los globos del suelo.

Los niños y las niñas han saltado para alcanzar los globos.

El paisaje sonoro ha sido determinante para que accedieran al espacio y empezaran a familiarizarse con él.

Los resultados han sido favorables, los niños y las niñas han disfrutado, han manipulado, han experimentado y han utilizado sus cinco sentidos. Además se han divertido en equipo. 


\section{Conclusiones}

Todos los niños y las niñas se quedaron sorprendidos y boquiabiertos cuando entraron a una de sus aulas y ya no era la misma, sino que se había transformado en un paisaje abstracto, diferente, lleno de color, de objetos sonoros, de globos, de confeti de papelitos y muchas cosas más. Los niños al inicio se quedaron estupefactos, mirando todo a su alrededor sin saber muy bien qué hacer, hasta que uno de ellos se echó para adelante. A medida que fue pasando el tiempo la motivación y el disfrute de los discentes fue aumentando; corrieron, se rieron, jugaron, pero sobre todo se ilusionaron y disfrutaron al máximo de nuestra instalación artística a la vez que desarrollaban sus cinco sentidos y se socializaban.

También les llamó la atención el ambiente sonoro, pues observamos que les recordaba a algo familiar y además se pusieron a dibujar en el mural al ritmo de la música y escogiendo los colores del Arco Iris de una forma inconsciente, pero que nosotras tras ver los videos hemos podido observar. Todos intentaban crear melodías que les agradaran e incluso pudimos ver como intentaban seguirse para hacer conseguir hacer el ritmo de los compañeros y de las compañeras.

Lo que más le gustaron fueron los túneles que tenían "cristales" de colores que les permitían ver el entorno de muchos colores. Cada túnel cuando ellos lo atravesaban hacía unos determinados ruidos debido a su textura y esto les llamó la atención. Además los túneles eran el paso inicial para entrar al entorno.

En un primer momento todos se fueron hacia los globos y a la bandeja de comida, aunque una vez que se tomaron la confianza practicaron con todo lo que había en el entorno. Hemos podido comprobar que se han cumplido todos los objetivos e incluso algunos que no estaban pensados previamente. Este proyecto no solo dejó sin palabras a los niños, sino que sus tutores quedaron muy contentos y satisfechos con nuestro trabajo. Además nos han invitado a volver a hacerlo con los niños y con las niñas de cuatro años. Nosotras dijimos que sí porque esta experiencia es para repetirla.

Los objetos sonoros han permanecido en buen estado porque los niños y las niñas han sido muy cuidadosos con el material, los túneles se quedaron en el colegio para utilizarlos en otro momento. Lo único que rompieron los niños fueron los globos porque se les veían entusiasmados con ello. Tras hacer el recorrido de las hojas secas en forma de caracol lo desalmaron para jugar con ellas.

En general, todo ha salido como esperábamos, los niños y las niñas se han mostrado muy participativos y activos en todo momento. Al finalizar esta maravillosa experiencia estética todos estaban muy animados, nos dieron las gracias y realizaron unos dibujos sobre lo que había significado para ellos nuestro trabajo. En casi todos los dibujos se aprecian objetos sonoros, dibujo de las mandalas, los globos, los túneles y también los colores del Arco Iris. Los niños se dibujan con una gran sonrisa y las tutoras nos han comentado que quedaron encantados.

Esta instalación artística ha funcionado perfectamente y hemos adquirido los objetivos propuestos. Es importante incluir el arte dentro de las aulas de educación Infantil porque aporta experiencias sensoriales, creativas, intuitivas, recreativas, sociales y comunicativas que permiten mejorar la socialización en las aulas y por supuesto conseguir cualquier objetivo didáctico.

Finalizo estas conclusiones afirmando que una” instalación artística” es ideal para alcanzar un desarrollo ideal de los niños y de las niñas en la etapa de Educación Infantil y para trabajar cualquier temática por abstracta que sea. 


\section{Referencias bibliográficas}

Abad Molina, Javier. (2008). Iniciativas de educación artística a través del Arte Contemporáneo para la Escuela Infantil (tesis doctoral). Madrid.

Arcos Luna, Francisco. (2015). “Colegio Montessori- Palau de Girona”. Cuadernos de Pedagogía. No 455 . España.

Carrasco Pérez, Esther. (2009). “Mis cinco sentidos”. Innovación y experiencias educativas. $\mathrm{N}^{\mathrm{o}} 21.1-14$.

Contreras. (1998). Didáctica de la Educación Física: un enfoque constructivista. España: Inde.

Callejón Chinchilla y Yanes Córdoba. (2012). “Creación de entornos de aprendizaje en Infantil: experiencia estética y juego”. Escuela abierta. $\mathrm{N}^{\circ}$ 15. 145-161.

Díaz-Obregón Cruzado, Raúl. (2003). Arte Contemporáneo y Educación Artística: Los valores potencialmente educativos de la instalación (tesis doctoral).Madrid: UNIVERSIDAD COMPLUTENSE DE MADRID- Facultad de Bellas Artes Departamento de Didáctica de la Expresión plástica.

García Higueras, Isabel. (2009). “Conocemos nuestros sentidos”. Innovación y experiencias educativas. $\mathrm{N}^{\circ} 25.1-15$.

Gennari, M. (1997 o 1999): La educación estética. Barcelona. Paidós.

Gutiérrez Pac, Clara. (2013-2014). “Los cinco sentidos en el arte”. Facultad de letras y de la educación. Universidad de la Rioja. TFG. 1-52.

Kortadi, Edorta. (1998). “La música y los cinco sentidos”. Cuadernos Musiker. № 10. 131-137.

Marie Shannon. (2013). "La teoría de las inteligencias múltiples en la enseñanza de español”. Salamanca.

Marín-Viadel, Ricardo y Roldán, Joaquín. (2014). “4 instrumentos cuantitativos y 3 instrumentos cualitativos en Investigación Educativa basada en las Artes Visuales”. Universidad de Granada. España, 1-40.

Read, H. (2010). Educación por el arte. Barcelona: Paidós educador.

Shafer Murray, R. (2006). Hacia Una Educación Sonora. México: Consejo Nacional para la Cultura y las Artes. Dirección General de Publicaciones. Radio Educación.

Shafer Murray, R. (1969). El nuevo paisaje sonoro. Canadá: Ricordi.

Solé i Gallart, Isabel. (1985). "Un reflexión sobre Montessori y Decroly”. Cuadernos de Pedagogía. No 126. España. 
Wild, Rebeca. (2013). "Vivir y aprender de manera coherente, en un desarrollo sostenible". Cuadernos de Pedagogía. No 434. España.

\section{WEBGRAFÍA}

CODIC. (s. F.) OBRA DE YAYOI KUSAMA. . [Acceso 06/12/15], de: https://www.didegipuzkoa. com/?q=es/node/350

Colegio Aldebarán. [Acceso 15/12/15], de: http://infantil-aldebaran.blogspot.com.es/2014/05/ descubriendo-el-arte-con-los-5-sentidos.html

Colegio Niña María de Linares. [Acceso 06/12/15], de: http://eininamarialinares.blogspot. com.es/

NIÑOS PINTANDO MÚSICA. [Acceso 6/12/2015], de: https://www.youtube.com/ watch?v=ZTK6ns2iNxk

SCHILLER NOCTURNE. [Acceso 06/12/15], de: https://www.youtube.com/ watch?v=EKbyGDIAvgk

SCRIABIN. (s. F.) Sinestesia: “el poder de ver la música”. [Acceso 06/12/15], de: http://tonomenor.blogspot.com.es/2012/01/sinestesia-el-poder-de-ver-la-musica.html

SONATAS DE SCRIABIN. [Acceso 06/12/15], de: https://www.youtube.com/ watch?v=kUGvRzTW2ME

SONIDOS DEL OTOÑO. [Acceso 06/12/15], de: https://www.youtube.com/watch?v=dGHDNzxzlY

Tornero y Domínguez. (2012). El método de ORFF. [Acceso 06/12/15], de: http:// lasmusicologas.blogspot.com.es/2012/04/el-metodo-orff.html

Visiónica'14. (2014). El arte sensorial. [Acceso 15/12/15], de: http://visionica14.tumblr.com/ artesensorial

\section{REFERENCIAS VISUALES}

Andy Goldsworthy. Mandalas Naturales. [Acceso 15/12/15], de: http://www.oei.es/ educacionartistica/primerainfancia/documentacion_artistas.php (En OEI: http://www.oei. es/)

Abad, Javier. Espiral. [Acceso 15/12/15], de: http://www.oei.es/educacionartistica/ primerainfancia/documentacion_artistas.php 
Buren, Daniel. Una de sus obras. [Acceso 15/12/15], de: https://www.flickr.com/photos/ commentdire/3835187136

Kusama, Yayoi. THE OBLITERATION ROOM. [Acceso 15/12/15], de: http://interactive.qag.qld. gov.au/looknowseeforever/works/obliteration_room/

Ferreiro y Ramírez. Lluvia de confeti. . [Acceso 15/12/15], de: http://es.paperblog.com/ macba-arte-contemporaneo-para-ninos-2113330/ 